\title{
Enchanting resilience: relations of care and people-place connections in agriculture
}

Article

Accepted Version

Herman, A. (2015) Enchanting resilience: relations of care and people-place connections in agriculture. Journal of Rural Studies, 42. pp. 102-111. ISSN 0743-0167 doi: https://doi.org/10.1016/j.jrurstud.2015.10.003 Available at https://centaur.reading.ac.uk/49102/

It is advisable to refer to the publisher's version if you intend to cite from the work. See Guidance on citing.

To link to this article DOI: http://dx.doi.org/10.1016/j.jrurstud.2015.10.003

Publisher: Elsevier

All outputs in CentAUR are protected by Intellectual Property Rights law, including copyright law. Copyright and IPR is retained by the creators or other copyright holders. Terms and conditions for use of this material are defined in the End User Agreement.

$\underline{\text { www.reading.ac.uk/centaur }}$

\section{CentAUR}


Central Archive at the University of Reading

Reading's research outputs online 
Enchanting Resilience: relations of care and people-place connections in agriculture

Agatha Herman (corresponding author)

Department of Geography and Environmental Science

School of Archaeology, Geography and Environmental Science

University of Reading

Whiteknights Campus

Reading

Berkshire

RG6 6AB

+44 (0) 1183787685

a.I.herman@reading.ac.uk 


\begin{abstract}
The practices and decision-making of contemporary agricultural producers are governed by a multitude of different, and sometimes competing, social, economic, regulatory, environmental and ethical imperatives. Understanding how they negotiate and adapt to the demands of this complex and dynamic environment is crucial in maintaining an economically and environmentally viable and resilient agricultural sector. This paper takes a socio-cultural approach to explore the development of social resilience within agriculture through an original and empirically grounded discussion of people-place connections amongst UK farmers. It positions enchantment as central in shaping farmers' embodied and experiential connections with their farms through establishing hopeful, disruptive and demanding ethical practices. Farms emerge as complex moral economies in which an expanded conceptualisation of the social entangles human and non-human actants in dynamic and contextual webs of power and responsibility. While acknowledging that all farms are embedded within broader, nested levels, this paper argues that it is at the micro-scale that the personal, contingent and embodied relations that connect farmers to their farms are experienced and which, in turn, govern their capacity to develop social resilience.
\end{abstract}




\section{Enchanting Resilience: relations of care and people-place connections in agriculture}

\section{Introduction}

"We have huge challenges ahead in boosting agricultural productivity, increasing resilience to the effects of climate change and variable weather patterns, effectively managing the countryside and natural environment ... we are really positive about the future of farming and our ability to create a sustainable, resilient and competitive industry"

Future of Farming Review Report (2013: foreword - 5)

At present, the world produces enough food to feed one and a half times the current global population (Holt-Giménez, Shattuck et al. 2012) but still more than 800 million people suffer from chronic hunger worldwide (World Food Programme 2014). While Holt-Giménez et al (2012: 595) argue that this highlights the fact that 'hunger is caused by poverty and inequality, not scarcity', distributional and equity issues remain largely unaddressed in conventional discourses surrounding the combating of global hunger. In 2009, the UN response called for world food production to double by 2050 (UN 2009), which both reinforced the hegemonic productivist paradigm (Silvasti 2003a, Holloway, Bear et al. 2014) and continued the pressure on producers to innovate in order to achieve this end. However, it must be recognised that this is not the only factor driving the governance of the agricultural sector, with concerns around global environmental change, public health, social responsibility, biosecurity, biodiversity and animal welfare, amongst others, adding further complexity and external pressures to contemporary producers' decisions and livelihoods (Ahnström, Hockert et al. 2008).

This establishes the farm as a complex moral economy in which the needs of, and responsibilities to, both human and non-human actants establishes a contingent, relational and collective entanglement of social relations (McEwan and Goodman 2010) in which what it means to be a 'good' farmer is highly contextual. Silvasti (2003a) notes the social scripting that occurs within every community to shape what is deemed to be acceptable and which, in this context, influences individuals' attitudes towards land, nature, 
environment and governance. Although there are clear differences in how different groups of farmers negotiate these issues - grounded in their varying ideologies, production practices and locations (Falconer 2000, Burton and Wilson 2006, Reimer, Thompson et al. 2012) - a common aim of all farmers is to maintain the continuity of their farm (Silvasti 2003a), particularly against the contemporary backdrop of 'volatile food prices, climate instability...and losses of resilience in agro-ecological and institutional food systems related to the restructuring of global agri-food regimes' (Cadieux and Blumberg 2013).

Understanding how individuals and communities can negotiate and adapt to this environment of unpredictable and sometimes crises-driven change is important for both government policy and farmers' own management responses (Maclean, Cuthill et al. 2014). Resilience thinking offers a useful conceptual framework to engage with processes and experiences of change and transformation, and is defined here as 'the capacity of a system to absorb disturbance and reorganise while undergoing change so as to still retain essentially the same function, structure, identity, and feedbacks' (Adger, Brown et al. 2011: 758). Resilience theories recognise the intertwined nature of social and ecological systems but, despite Adger (2000) questioning the relationship between social and ecological resilience 15 years ago, Maclean et al (2014) argue that the inherent challenges in bringing the social and ecological together within resilience theories has left understandings of the social elements lagging behind. Through engaging with the conceptualisations prevalent in the social and health sciences, academics have begun to focus attention on 'social resilience' through work on community resilience (Magis 2010, Berkes and Ross 2013) and social factors in international development (Cuthill, Ross et al. 2008, Dale, Ling et al. 2008). Following Maclean et al (2014: 146) I understand social resilience as 'the way in which individuals, communities and societies adapt, transform, and potentially become stronger when faced with environmental, social, economic or political challenges', and in this paper I work to expand understandings around this critical but under-theorised concept.

To date studies exploring resilience in agriculture have largely focused on financial and economic approaches (Maleksaeidi and Karami 2013, Ranjan 2014); agro-ecological management methods (Björklund, Araya et al. 2012); subsidies and policy (Hammond, Berardi et al. 2013); and mental health (Greenhill, King et al. 2009, Hunt, Vanclay et al. 2011). However, farming is not purely a business or 
mechanism for policy implementation but can also be an immersive lifestyle grounded in embodied, experiential relations. Increasingly, the socio-cultural factors within resilience are being brought to the fore with Dwiartama and Rosin (2014) reflecting on an ANT approach to resilience and Forney and Stock (2014) discussing the impact of farm conversion on succession, the community and the family farm. Here, I build on this existing research to further develop this more holistic understanding, embedding resilience within the internal and external socio-cultural understandings, practices and networks in which all farmers are enmeshed.

A consensus of thought has established people-place connections as one of the key attributes of social resilience (Berkes and Ross 2013, Maclean, Cuthill et al. 2014) and yet Berkes and Ross (2013: 17) comment that 'more work is needed about the values and behaviour that bond communities and cultures with their environment'. In this paper I argue that a key element in structuring and enhancing these people-place connections for farmers is enchantment. This refers to an embodied encounter that connects an individual 'in an affirmative way to existence' (Bennett 2001: 156) and, I argue, to the places or things that trigger this emotional and experiential being-in-the-world; in turn, this establishes 'relations between peoples and places and significantly expands intersubjective space-time beyond the self' (Tilley 2006: 14). I position enchantment as being triggered by both positive and negative emotional experiences, which moves behind the romanticising discourses of the 'rural idyll' and provides a more grounded sense of the emotional geographies of enchantment. As Wilson (2010) comments resilience is both an outcome and a process, and so here I analyse the moral economies of the farm as everyday doings that ground ethical obligations in concrete relationalities in the making (McEwan and Goodman 2010).

In this paper, I first provide a background to farmers' engagements and relationships with their farms before positioning the concept of social resilience, and conceptualising its relationship with enchantment. I then introduce the research context, which is positioned through the key stressors that are currently impacting on farmers in this area and grounds the subsequent empirical discussion. The paper concludes that while panarchy suggests that attention needs to be paid to all levels of a system, and acknowledges the nested nature of these levels, it is at the micro-scale that farmers experience and practice their 
connections to the land, which forms a key part of their social resilience. Drawing on 19 semi-structured interviews conducted in 2014 with farmers and industry stakeholders in Southern UK, this paper offers an original, socio-cultural conceptualisation of the establishment and maintenance of farmers' connections to the land; this in turn opens out the inherent social aspects of resilience because, as an English farmer commented in Harrison et al's (1998: 311) study, 'if it was just a matter of economics we would not be here'.

\section{Agri-Cultures: the relations between farmers and their farms}

Although agricultural geographies were slow to engage with the cultural turn (Morris and Evans 1999), the shift to more socio-cultural approaches over the last decade or so has been critical in providing more grounded and qualitative understandings of the micro-geographical socio-spatial relations that govern how farmers engage with and understand their environments (Geoghegan and Leyshon 2012). By exploring, for example, 'everyday experiences' (Rose 2002: 457) a more complex understanding of the discourses of power, relations between nature and society and role of 'more-than-human' actants has emerged, which in turn has moved away from homogenising agriculture into a single cultural enclave, recognising its inherent diversity (Morris and Evans 2004). Interactions with the farming landscape remain, however, a habitual element in every farmer's life, whether physically or virtually, but landscapes are always sites of power, being 'contested, worked and reworked by people according to particular individual, social and political circumstances...they are always in process... structures of feeling, palimpsests of past and present' (Tilley 2006: 7). Agricultural landscapes are thus lived and practised, and so cannot be understood in isolation from the internal and external discourses that govern them (Gray

1996). As Marsden and Sonnino (2008) note agrarian policy increasingly emphasises the essential 'multifunctionality' of agriculture (Wilson 2008, Wilson 2009) within a diverse rural economy:

'Landscape is not primarily to be conserved or preserved, but to be cultivated and shaped'

(Silvasti 2003a: 147) 
Whether farmers are organic, biodynamic or conventional, their very role as producers of food and commodities indicates a common view that the role of a farmer is to cultivate land, although they differ in their practice of this. During my research both organic and conventional farmers commented on their historic and current role in shaping what is often seen as 'natural' countryside by the general public but which is all farmed or managed in some way. ${ }^{1}$ This allows many farmers to position themselves as 'stewards' or 'custodians' of the rural landscape although their scripting of what these terms means often differs from those of, for example, conservationists (Ahnström, Hockert et al. 2008). Carr and Tait (1991) stated that farmers often described unproductive land negatively as derelict, wasted, neglected and overgrown disorder while, in contrast, farmed areas were tidy, orderly, clean and decent. Indeed the visual appearance of a farm was positioned as a public expression of whether they were being a 'good steward' and, by extension a 'good farmer', or not (Ryan, Erickson et al. 2003). However, biological conservationists are often sceptical as to these claims of stewardship because conserving an agricultural landscape and way of life does not necessarily equate to their goal of a rich and biodiverse habitat, which is also often untidy 'wilderness' (Carr and Tait 1991, Ahnström, Hockert et al. 2008). This leads to farmers often being simultaneously positioned as custodians and polluters, reflecting both these differences in definition as well as the tensions on a farm between farming 'ethically' and the stressors that can make this difficult to achieve (Holloway, Bear et al. 2014). The contested space around conservation offers some interesting insights into farmers' attitudes towards their land, with two common discourses being:

\footnotetext{
${ }^{1}$ Here, 'organic' farmers are those certified under the UK's Soil Association while 'conventional' farmers are not. While this offers a clear definition, it remains a problematic distinction as there was considerable slippage in terms of practices and ideology between the two groups; the potential exclusions that this definition entails must also be acknowledged for the Soil Association only promotes a particular conceptualisation and operationalisation of the discourse of 'organics'.
} 
1. A good farmer would never damage or destroy land and water because productive land and clean water are the essential conditions for continuing the farm, therefore farming is selfevidently ecological (Harrison, Burgess et al. 1998, Silvasti 2003a).

2. Managing and cultivating the same land for generations gives farmers a unique local knowledge and therefore a good understanding of the contextual care requirements of the land and how to conserve it for future generations (Bieling and Plieninger 2003, Ahnström, Hockert et al. 2008).

This perception of a close and historically grounded relationship to their farm means that farmers often contest the advice of conservationists, challenging the latter's monopoly on knowledge and arguing that their experiential learning is as valid as that of these 'people in offices' (Harrison, Burgess et al. 1998: 311). As Riley (2008) notes the 'experts' who author agri-environmental policies often consider farmers to have environmentally beneficial 'traditional' skills but to be largely lacking the expertise needed for 'appropriate' land management. This leads to discussions about the role farmers should play in developing agri-environmental schemes and the extent to which interchange occurs between the 'lay' and 'expert' knowledge cultures (Morris 2006).

This leads us back to what constitutes a 'good farmer'. What should they be doing with their time and resources? What are the appropriate relations between farmer and stock? In the European Union (EU), agriculture has long been heavily subsidised with subsidies accessed through completing forms; this means that a significant proportion of farm income is earned behind a desk rather than in the field (Silvasti 2003a). In Silvasti's (ibid) study farmers commented that they would rather earn money doing 'real farm work', which highlights that, for many, it is the nature of the work that matters as well as the economic return; as Allison (1996: 142) notes 'farmers want to farm'. Given the negative psychological impacts of feeling that one is not being a 'good farmer' (Hansson and Lagerkvist 2012), the way in which (in)adequacy can be read through the landscape in different ways by passing conservationists, the public, policymakers and other farmers can act as a significant stressor particularly if the judge adheres to an alternative social script as to what constitutes 'good' farming. Burton (2004) developed the idea of hedgerow or roadside farming, noting that farmers often, perhaps subconsciously, put greater effort into the most visible spaces of their farm, since physical appearance is a key indicator of 'good farming' for 
conventional farmers and therefore in making, or breaking, a farm's reputation. For example, organic and conventional farmers evaluate success in different terms (Reimer, Thompson et al. 2012); although continuing productivist attitudes amongst the latter have led to the former being framed as 'pretend' farmers (Silvasti 2003a) as organics has become more mainstream the business opportunities it offers are increasingly recognised by conventional farmers (Sutherland 2013). While a visual display of farming skills and nurturing ability remains important (Burton, Kuczera et al. 2008), Sutherland (2013) argues that changing opinions around organic agriculture are changing the broader symbolic frameworks of what is understood as 'good farming' and the landscapes that represent this.

This diversity of ideologies highlights the multiple and dynamic scripts, which shape how producers relate to their farms; as Reimer et al (2012: 33) state 'farmer decision-making processes are complex and variable but it is impossible to completely separate decisions about conservation from the need to generate a sustainable income from agricultural production'. Ultimately a farm must be financially viable, meaning that how a farmer manages their farm is linked to the structural and social features of the economy in which they operate, which is itself not a level playing field (Falconer 2000). Therefore, when analysing how they adapt to continue farming in this complex and highly contingent global arena we need to 'look outside the farm and inside the farmer' (Ahnström, Hockert et al. 2008: 43), acknowledging the internal and external factors that govern the development of resilience, and social resilience in particular.

\section{Placing Social Resilience: enchantment and ethical relations of care}

Broadly, resilience conceptualises how individuals, communities and institutions thrive in environments characterised by 'change, uncertainty, unpredictability and surprise' (Berkes and Ross 2013: 6), and so increase their capacity or, perhaps, capability to cope with stress (Adger 2000). A resilient socioecological system is one that is in a state of dynamic equilibrium and which, as the result of a stressor, either remains within certain critical thresholds or transforms into a new system (Folke 2006). Berkes and Ross (2013) note that there may be multiple stable states in which a system can exist - adaptable yet 
continuous - but also that resilience should not be taken as always being a positive state; poverty or poor animal welfare practices can be highly resilient but this does not make them desirable.

In Reimer et al's (2012: 33) study they state that a common sentiment amongst Indiana farmers was 'it all comes back to the economy'. However, following Sayer (2007), all economies generate impacts that have ethical implications and are founded on some understanding of rights and responsibilities. Therefore, while economic/financial viability and resilience is critical, this is mediated by the noneconomic norms and obligations that also shape a farmer's social and political relations and experiences (Arnold 2001). As Thompson (1971) discusses, the moral economy is what distinguishes legitimate from illegitimate practices; I argue that, while resilience within agriculture is about how the farm/farmer adapts in response to a disturbance, this can only be done within the moral economies surrounding farming. These are shaped by normalised social scripts of what is acceptable to do in order to continue and, moreover, to continue as a 'good' farmer. The complexity of understanding resilience means that there is no single indicator that can capture its totality (Adger 2000); it is therefore best conceptualised as a Foucauldian assemblage (Howell 2015) of which 'control is at best partial and outcomes are nearly always uncertain' (Berkes and Ross 2013: 13). This unpredictability or uncertainty is reflected in Beck's (1997) argument that often the most important impacts of our choices and decisions are unintentional 'side effects', highlighting the contingency and dynamism of being resilient in an uncertain and surprising world.

While there remains a knowledge gap regarding the social elements of resilience, Maclean et al (2014) work to address this by proposing six key attributes: knowledge, skills and learning; community networks; people-place connections; community infrastructure; diverse and innovative economies; and engaged governance. Recognising the necessarily interconnected nature of these elements, this paper focuses on one in particular: people-place connections because these 'acknowledge human-environment interdependencies and connections' (ibid: 150), which are foundational to agricultural practices and relations. Both Berkes and Ross (2013) and Maclean et al (2014) discuss the importance of place-based attachments to enhancing social resilience through a focus on Aboriginal communities' discourse of 'healthy country, healthy people'. This acknowledges the interdependent relationship between the 
resilience of a community or individual and the resilience of their environment but is based on more than simply survival or pragmatism. It is also the historical intimacy with, and cultural responsibility to, the land that is built up through repeated, every day or unexpected engagements, which develop the peopleplace connections that inspire commitment to protecting and preserving these places, and so motivate resilient attitudes and practices.

Here, I focus on the actions and relations that connect farmers to their farms, the 'special, sensual, and intimate attachment...[and] feeling of being in their proper place' discussed by Gray (1999: 441). Farms and farmers are clearly nested within a panarchy of interconnected socio-economic, political, cultural and environmental systems, which they cannot operate outside of. While the 'system' is emphasised in socioecological resilience literatures, and discussions in the social and health sciences are increasingly addressing the community level (Magis 2010, Berkes and Ross 2013, Wilson 2015), here - while acknowledging this broader context - I am focusing on the micro scale of farmers' embodied engagements with the particular places of their farms. Maclean et al's (2014) social resilience framework, alongside Greenhill et al's (2009) work on farmers' mental health, is useful in reflecting on this personal scale as they draw out the resources, characteristics and processes needed for an individual to have the capacity to adapt to disturbances, while retaining essentially the same identity, function and relations. To be resilient, therefore, an individual must have the appropriate knowledge and skills including relevant practical, theoretical and interpersonal abilities; connections to community networks and the capability to draw on social capital; a willingness to learn; an openness to change; the capability to access necessary resources; and a grounding in place. Together these give the individual both the capacity and the motivation to take action to be(come) resilient with the relationship with place, I argue, having the potential to act as a particularly critical driver for social resilience at this personal scale.

As Setten (2004: 395) notes farming landscapes are produced through a complex interaction of embodied customary practices that are the result of knowledges gained 'through a constant engagement with the land through their [farmers'] agricultural practices', common discourses within the area and the moral framework of farmers' own past and ancestral practices: 
'...the material landscape becomes indivisible from those people who have historically managed and created that landscape... [this] guides and constrains how practices are performed today' (Riley 2008: 1285)

People engage with a landscape both through how they physically alter it and how they are located within and constituted by it (Saugeres, 2002). The latter recognises the active nature of places and their capacity to impact on us with landscape becoming defined in terms of 'contact, immersion and immediacy... [with] stress placed upon the central role of bodily presence - of sensuous, tactile and experiential being - in the co-constitution of self and landscape' (Wylie 2009: 278-279). One way in which we can conceptualise this emotional and experiential relationship of being-in-the-world is through Bennett's (2001) enchantment. This is 'to be transfixed, spellbound' (ibid: 5) by an embodied encounter that, through a simultaneous sense of strangeness and familiarity, connects us into 'a mood of fullness' that celebrates the 'wondrous complexity of life' (Bennett 2001: 7-110). Similar language emerges in Romantic discussions around sublime 'natural' landscapes although Bennett (ibid: 171) notes that both natural and cultural artefacts and places function as 'reservoirs of enchantment'. The 'enchanting' capability of a landscape is contextual and relational since 'the same place at the same moment will be experienced differently by different people; the same place, at different moments, will be experienced differently by the same person' (Bender, 2006 in Tilley, 2006: 7). A landscape can therefore work to establish very particular attachments for farmers (Mueller Worster and Abrams 2005), which are tempered through 'memory, observation and conversation' (Geoghegan and Leyshon 2012: 64). Bennett (2001) contends that the affirmative and embodied nature of enchanting encounters makes them more emotionally engaging, which in turn acts to motivate an ethical response of care (Woodyer and Geoghegan 2012).

Social resilience is about building on strengths, rather than focusing on vulnerabilities (Berkes and Ross 2013), and enhancement, bouncing forwards rather than back (Howell 2015), which connects into the affirmative nature of enchantment. In his discussion of resilience ethics, Chandler (2013) notes how the individual is increasingly seen as a socially, environmentally and materially embedded subject; our associational connectivity leads to us becoming 'responsible for the world but capable only of working to 
change the world through working on our own ethical self-growth' (ibid: 178). This pushing of agency to the scale of the everyday and onto the self-reflexivity of the individual arguably positions resilience as a tool of neoliberal governmentality and, whether we focus on resilience as responsibilisation or enhancement, the individual remains central (Howell 2015). For Chandler (2013) this can lead to too much attention being placed on the self, a shifting of blame between the scales and a more paternalistic style of state-citizen relation in which the former tries to educate the latter to take responsibility for their actions. More seriously this focus on the 'ethical self' leads to less interest in a specific problem (ibid). While enchantment is about an individual's embodied and personal relationship with a place, the ethical response of care that this promotes connects into broader mobilisations around stewardship, the 'good' farmer and collective responsibility to both land and society. Enchantment is thus part of the broader moral economy that connects farmers to their farms, and is key in driving them 'to continue to build and enhance their adaptive capacity to cope with change' (Maclean, Cuthill et al. 2014: 150).

People-place connections can manifest in myriad different ways and the embodied relations enhanced by enchanting experiences are also not all the same. For some farmers, this may result in a perceived responsibility to the environment itself and so ecologically sound practices. For others, the connection to the land may emphasize their position as a farmer, leading them to follow particular moral scripts to, for example, produce maximum yields at peak efficiency. For others still, the connection may enforce the need to be economically profitable in order to preserve the farm. As Holloway et al (2014: 189) state 'discussions of ethics of care demand a focus on the specificity and contingency, and hence the immanence, of always emplaced ethical relations and embodied encounters'. If we understand ethics as the habitual actions involved in constructing a particular life and identity (Barnett, Cloke et al. 2005), we can see that ethics are always situated and contextual, with the capacity to be ambiguous and complex. In turn this highlights the multiplicity of ways in which people-place connections may manifest as material relations and practices. It must be remembered that these connections include non-humans, and so these moral economies are also informed by ideas about the treatment of nature and nonhumans (Freidberg 2014), including animals, plants, chemicals, machinery, buildings and soils. Agency and adaptive capacity are key elements in building social resilience (Berkes and Ross 2013, Maleksaeidi 
and Karami 2013), which also depends on the development of strong social networks (Maclean, Cuthill et al. 2014). Following Latour (2005), non-human actants also have agency and so, if care is understand as a way of relating to (broadly defined) others, then reflecting on people-place connections demands an expanded and collective understanding of the social (McEwan and Goodman 2010), which recognises the role of non-humans in developing and maintaining the (social) resilience of a farm(er). Moral economies are embedded in ongoing, concrete social relations (Arnold 2001) and so social resilience on the farm emerges as a complex and dynamic entanglement of human and non-human actants, practices and relations.

People-place relations also have a temporal element with Hammond et al (2013) highlighting that for many farmers a desirable goal is to own and work farmland in a way that is consistent with their family and cultural histories. Ownership in particular emerges as key in shaping attitudes towards a farm as it offers a connection both to previous and future generations, allowing relations of care to cross temporal, if not spatial, divides. Silvasti (2003a: 143) argues that 'ownership weaves strong emotional ties between the family and the land. Possession reinforces and justifies family strategies for maintaining continuity of the farm, and family strategies strengthen the ties between the land and the family'. Ownership arguably enhances the capability and agency of the farmer to control and shape the farm but while family farms and ownership may be emphasized in the literatures we must remember that not all farms are owned by those who work them. Thinking only about owner-farmers highlights some of the exclusions and inequities that exist within agricultural systems in which many workers globally are subject to precarious, exploitative and poor labour conditions (Rye and Andrzejewska 2010, Hall, Wisborg et al. 2013) and are excluded from legislative protection (Barnetson 2012). They are clearly unlikely to have enchanting and affirmative experiences connected with the farms and, indeed, these will not even be the experiences of all farmers, whether owner or tenant. An individual's relationship with the land is just that, individual, and there is significant heterogeneity in terms of both whether and how a farmer/worker connects with a place, and how they understand resilience. As Ranjan (2014) questions, what does it mean to be resilient? Is it about preserving the agricultural lifestyle? Being financially stable? Environmentally responsible? Wealthy? Or able to find alternative employment if farming becomes unsustainable? 
Furthermore, can an individual be resilient in only one place and time, or to only one stressor but not others (Berkes and Ross 2013)?

Enchantment is only one possible form of emotional attachment shaping people-place connections and, while this only explores the experiences of a particular group involved in agriculture, is nonetheless critical to understand and conceptualise. Social resilience takes a variety of forms and a farm is always embedded within larger social and policy scales (Hammond, Berardi et al. 2013); a resilient individual positively contributes to the resilience of a community (Berkes and Ross 2013) and so how enchantment shapes an individual's experience and achievement of social resilience has broader implications for farming and rural communities as a whole. Before moving on to empirically discuss these farmer-place connections, I first introduce the research context.

\section{Research Context}

This paper draws on 19 interviews conducted in 2014 with farmers and industry representatives from the south of England (see Table 1) as well as policy documents from government, unions and NGOs. This region has a diverse range of producers with variety in both farm size (the sample ranged from seven to 1100 acres) and type (horticulture, arable, dairy and livestock), which allows for a broad and comparative understanding of farmers' connections to their farms, and the varying and multiple stressors that test their social resilience. Despite the presence of large agri-businesses, the UK farming sector remains largely structured around family-owned and run micro-businesses although in recent years there has been a decrease in the total number of agricultural holdings, particularly those under 50 hectares, and a fall in the total income from farming (DEFRA 2012), which highlights the increasing challenges in terms of maintaining economic viability.

TABLE 1 
While interviewees identified a range of macro-scale stressors, including climatic uncertainty and market volatility (DEFRA 2013), two themes in particular dominated their conversations - regulations and the perception of disconnections - which can be translated into a central issue around agency. These are familiar narratives for farmers around the world but England's diverse and dynamic agricultural sector provides a useful lens through which to explore farmers' social resilience against the backdrop of these multiple and competing demands; for example the partial 'greening' of agricultural policy through the UK's interpretation of CAP (Marsden and Sonnino 2008) and England's position as an important organic producer (Zanoli, Gambelli et al. 2014) potentially conflicts with the Rural Development Programme for England's funding focus on increasing the productivity of farming (gov.uk 2015). Therefore, it is necessary to contextualise the subsequent empirical discussion by first introducing some of the key stressors that are impacting on English farmers.

\subsection{Stresses and Stressors: two contemporary challenges within agriculture}

As discussed in section 2, farmers often seek to contest the monopoly on knowledge performed by policymakers and which, amongst my interviewees, was reflected in both the general confusion over the overly-complicated and 'unnecessary' bureaucracy of statutory compliance (DEFRA, Interview, 16/05/14; Farming Regulation Task Force 2011), and a perceived disconnect between lay and 'expert' knowledges. This translated at the ground level into both critiques of the processes of compliance and uncertainty over exactly how to comply. With regulations often being discussed predominantly at a high level, particularly in the EU, this contributed to the impression that policymakers are aiming for goals that farmers are not party to and so are unable to challenge (Harrison, Burgess et al. 1998). The whole paperwork process was widely considered to be overly complex and, while DEFRA (2013) acknowledges the difficulties in co-ordinating multiple schemes originating from various scales, duplication of efforts persists in certain areas.

The Farming Regulation Task Force (2011) suggest that the principles of earned recognition could be used to reduce the regulatory burden for compliant producers since, as the farmers acknowledged, 'you need regulation for the bad boys but the good ones are going to be streets ahead anyway' (C/Arable 2, 
24/07/14). However, this system would contain a certain degree of trust and, given that farmers felt that they were considered to be inherently untrustworthy by regulators, highlights an issue in terms of social capital:

'Sometimes you do make mistakes and they, well, they just won't accept any excuse at all... they just strike the fear of God into you because they're terrible, you can end up in prison... you're always guilty until proved innocent' (O/Dairy A, 18/06/14)

There was a sense that, particularly with new inspectors, the whole process was too impersonal and that given the often very visceral connections farmers have with their land and/or animals, greater empathy and flexibility was needed in the interpretation of regulations and the way in which inspections and other procedures were conducted. This perceived lack of consideration arguably emphasized the feelings of disconnection with regulations and regulators as, while the majority of farmers accepted the need for a certain amount of legislation and its corresponding paperwork, they argued that the reality of how regulations impacted at the farm level demonstrated a lack of practical knowledge (Farming Regulation Task Force 2011) and empathy at the level of the legislators:

'I hate to say this in front of you, but they come out of university and haven't had any real practical experience and they go by the book... And most of them have written the books in the first place, with the result that you haven't got that practical input and you haven't got that experience of working on the ground with the people that you used to have' (C/Dairy 1,17/06/14)

'...any one thing, stand alone, you say, well I can see the sense in that, because there is sense in it. But when you have 1000 of those sensible little things it then becomes impossible to do' (C/Mixed 2, $19 / 06 / 14)$

Nordström Källström and Ljung (2005) discuss how the lack of control over decision-making is the most important factor that hinders farmers' ability to continue farming, while Emery (2015) highlights how the ideal of autonomy can act to disempower farmers through hindering the development of cooperation and collective power because of a misrecognition of from whom independence is sought. A sense of a lack of agency or power over regulations - both what they demand and how they impact on farm practices - may impact farmers' adaptive capacity, weakening their connections to the farm by reducing 
their autonomy (Stock and Forney 2014) and capability to choose how it is operated. This lack of agency was particularly apparent in the common feeling amongst farmers that the different contexts and environmental realities on individual farms are not taken into account in 'one-size-fits-all' agrienvironmental strategies:

'We're paid to have lapwing plots and we've always got lapwings on the farm but the lapwing plot, where they want it, the lapwings don't like that field. And we know that and I've told them that but they have to have it in that field...so we've got a plot which they're paying about $£ 1,500$ for a year and we know lapwings will never go there... But they nest somewhere else, of which they nest there anyway so they didn't need to pay for it ... I suppose they have to spend the money somehow...' (O/Arable, 28/05/14)

This perceived lack of understanding went beyond relations between farmers and regulators as the interviewees often referred to an increasing disconnection between the majority urban population and rural spaces and practices. This separation shapes public understandings of agriculture with the majority of information about, for example, farm profitability and farmers' socio-environmental attitudes coming from media reports on farmers' pro-immigration arguments (Darwar 2013) or farm subsidies as a transfer of money to the rich (Monbiot 2013). In the case of the latter, while average farm sizes are growing and so the single-farm payment is increasing per farm, for the majority of farmers subsidies represent either the profit or mean that the farm simply breaks even (O/Mixed 1, 16/06/14; O/Arable, 28/05/14). At present, agricultural commodities are a demand-driven market - 'agriculture is the only industry in the world that we'll allow someone else to dictate the price of our finished products' (O/Mixed 1, 16/06/14) - and this disempowerment within the supply chain leaves profitability and, indeed, economic viability as the chief concern of farmers; its impact on their capability to achieve social or environmental targets increases the mental and physical pressure they experience.

The constraints placed by finance on farmers' capability to achieve their aims or adhere to their vision of 'good' farming highlights the constant and underlying importance of the economy; while farmers may have particular ideals or sentiments that structure and influence their practices ultimately 'these are reinforced, compromised or overridden by economic pressures' (Sayer 2007: 262). Nonetheless, all of 
the farmers interviewed are adapting or have adapted their practices in order to respond to these and other stressors, whether by going organic, changing their product or going into more value-added processing activities. To farmers, this was fundamentally grounded in ensuring economic viability but I would argue that this alone does not account for their persistence and tenacity; as one farmer commented 'there's three reasons for the sale of land and they all begin with D; it's death, divorce and debt. That's the only reasons...these farms aren't sold because the people don't like what they're doing' (O/Arable, 28/05/14). In the following section I empirically explore and analyse enchantment as a form of people-place connection, which supports farmers' capability to develop social resilience.

\section{Enchanting Agriculture}

'To be enchanted is to be struck and shaken by the extraordinary that lives amid the familiar and the everyday'

Bennett (2001: 4)

While Schneider (1993) focuses more on enchantment as through engagements with the peculiar and the unknown, I would argue that the real strength of 'enchantment' lies in its capability to provoke a revaluation of the known and the everyday (Bennett 2001, Holloway 2003). While I agree with Ramsay (2009) that Bennett's (2001) embodied experience of enchantment seems overly dramatic, the feeling of being struck, shaken or spellbound may only be momentary but even a brief rupture can be enough to provoke a reconfigured sense or renewed appreciation of a long-familiar object, subject or landscape; a surprising encounter need not be with something unknown. In fact, for Woodyer and Geoghegan (2012: 205 , emphasis added), 'appreciating enchantment in the ordinary requires attention to the possibilities for how our world might be otherwise'. By confusing or refusing familiar spaces or temporalities, enchantment challenges us to constantly re-imagine a world in which one can flourish (Burlein and Orr 2012) and so 'offers a practical means of negotiating the bitter-sweet, of being energised rather than paralysed' (Woodyer and Geoghegan 2012: 209) by discontinuities.

Thompson and Coskuner-Balli (2007) briefly comment on the enchantment experienced by community supported agriculture (CSA) producers, highlighting one farmer who had 'always been captivated by root 
vegetables' (ibid: 284). To them, the capacity to enchant is contingent on the small scale of CSA, which allows for a more intimate practice of production. Similarly embodied feelings of connection emerged through discussions with organic producers around their relationships to their produce, the land and the soil:

'...everything has to be done by hand, we can't spray a crop with weed killers, we have to go along on our hands and knees picking out every single weed. And when it's, when the carrots have just come up and the weeds are about the same size, this is a microscopic job, with a little fine knife that you flip the weeds. It takes days to weed the carrots, and that's just the carrots ... I can't stand it [waste], and everyone's [organic producers] the same, because we know what's gone into producing it, and I think it's just slightly different perhaps, large scale conventional growers are just slightly more divorced from all that really... you're not going to waste a carrot... they're all very meaningful...' (O/Horticulture 2, 08/07/14)

'...we have one field that we get ragwort, which is terrible... I am having to manually pull and that is a nightmare for me. And I spend a week up there pulling the stuff and I, by the end of it, I'm angry as anything...' (O/Dairy 2, 01/07/14)

As Hayden and Buck (2012: 332) state 'food weaves the people-environment web', and these visceral descriptive accounts of some of the practices of farming highlight the very embodied relationships with the land and, for example, vegetables that the farmers have. The wonder and excitement evoked by a successful carrot harvest is therefore made more significant through the knowledge of the care that was involved in its production. Being on your hands and knees carefully separating carrots from weeds enchants simply through disrupting the normal viewpoint of the field by engaging with the soil, the plants and the micro-fauna in a tactile way at a different scale to usual. In a somewhat different way, while rage against ragwort may not seem like Bennett's (2001) positive 'sense of fullness', it still provokes a revaluation of the field and the discontinuity that ragwort enacts demands an active consideration of how the field can be improved; the ragwort elicits an emotional response, which can leave the recipient as shaken as the joy that can be found in carrots. 
For Ritzer (2011) the standardisation and industrialisation of mainstream, modern agriculture precludes the possibilities of enchantment that these very ground-level accounts allow for; technologies change the distance between farm and mouth (Freidberg 2014), and farm and farmer, making relations with food and the environment more opaque. Holloway et al (2014: 189) argue that 'a technology frames the world: it becomes a means of disclosing the world to use and of making it available in particular ways...reducing the world to a set of resources and cutting us off from other relationships with it'. While this clearly precludes certain, 'hands on' relationships I would argue that this does not close off all the possibilities for enchantment. For Bennett (2001) man-made objects and places can elicit an embodied response and, while a technology may shape your experience of the world, it does not remove you from it. Therefore, while the connections between a conventional, industrial farmer and their land/produce is different, as I found when conducting an interview while hauling grain, a tractor with its sounds, smells, heat and bouncing rhythms remains a very embodied and experiential practice. Equally, technology does not always insulate a farmer from the unpredictability of agriculture - weather remains uncertain, cows refuse to attend an automatic milking system and machinery breaks down - which can all act as disjunctures. Therefore, while having different social scripts as to what constitutes 'good' farming, conventional farmers can still feel responsibility to the land, the consumer, the product and the soil:

'But if it just bakes out and goes hard and dry it's not good for soil biology, not good for the work... it's either going to be really rock hard and dry when it comes to plant it or it's going to get wet and go really slimy. Whereas if it's got something growing in it, those plants will mop up nutrients, give me some cover, harvest sunlight, put some sunlight back in, so we're going to grow carbon, and growing organic matter, really, and it will keep a consistency to the soil, so we feed the worms, the roots will help aerate the soil, help with the infiltration of water...So that's why we're doing it, really... Even though we're not going to make any money from the crop, it's almost investing in soil...' (C/Arable 2, 24/07/14)

Although this more productivist discussion is different to the very tactile spaces and descriptions in, for example, CSA (Thompson and Coskuner-Balli 2007, Hayden and Buck 2012), non-human actants animals, soil, plants, landscape, weather, buildings, machinery and chemicals - all still have, admittedly to 
varying degrees, agency within conventional agricultural landscapes that can 'deflect, alter and interrupt the flow of everyday life' (Ramsay 2009: 200). Here the soil is part of the relational network of human, nonhuman and technological entities that produces the 'farm' (Holloway 2002, Yarwood and Evans 2006) and, through its dynamic nature, disrupts the view of the field as an inert, passive space (Soil Association, Interview, 25/03/14); nonetheless, power relations between humans and non-humans are not equal (Holloway, Morris et al. 2009).

While all farmers are constantly dealing with these 'more-than-human' forces and relations, unexpected moments of wonder seemed to be particularly provoked in those working with animals:

'...when I was milking the cows I liked 80 as about the right number, then you know each one by name and everything. And we multiple-suckle some of our calves so they're, some of them are fed on with a teat, not with a bucket. We feed them with the sucking teat... And those, l, more often than not, do those... and each one of those knows me by name. They know me by my voice. When they come in they go up the passageway to the box and they stop at the box they've got to go in. You just open the box and let them in, and when it's coming to come out you say, "OK, come on Maddie", or "come on 62" or "come on Brownie" and they come out, walk out, and go out in the field. Absolutely super' (C/Dairy 1, 17/06/14)

‘...Because we only milk 50 cows so you can individually know every single one of them...he'll know when they come in, in a different order into the parlour, just when they are behaving differently...' (O/Dairy 2, 01/07/14)

All the animal farmers spoke with real passion about their animals, mentioning characters and incidents that made them laugh or smile such as getting a lamb to suckle, or how a calf would come running when they entered the barn or the power politics within their herds (see Gray 1996, Holloway 2003, Burton, Peoples et al. 2012, Sellick and Yarwood 2013). A lot of farming is about doing the same things - walking the same routes and following the same routines - because this is often the only way to balance all of the constantly changing demands. However, the inherent uncertainty to farming disrupts these habitual encounters, even if only in very subtle ways, which allows one to 'notice new colours, discern details 
previously ignored... as familiar landscapes of sense sharpen and intensify' (Bennett 2001: 5). I suggest that it is 'enchantment' which moves farmers beyond the routine by creating the opportunities for them to (re)engage with their farm's landscape, driving farmers to continue to build and enhance their adaptive capacity to cope with change (Maclean, Cuthill et al. 2014). Context is therefore important as the time of year, the activity, the location and the motivation all shape how the moment is experienced and so the potential for an unexpected encounter. Ramsay (2009: 209) conceptualises the 'residual enchantment' of objects, which refers to the 'affective trace of the past which necessarily haunts the present', building on this I would suggest that the spaces, actants and practices of the farm also induce a forward-looking sense of hope, potential and opportunity, which encourages resilient thinking and practices.

One of the dangers of engaging with enchantment is the potential for this to be seen as romanticising farming, connecting into bucolic representations of the rural idyll. However, in my interpretation while enchantment is admittedly positioned as ultimately a positive force, the disjunctures that provoke shock/wonder may not always be experienced in a positive way. Enchantment is inherently unsettling and engagements with animals, insects, plants and machinery can provoke joy, attachment, love and care but equally feelings of disquiet, vulnerability and anger, as some of the CSA participants in Hayden and Buck's (2012) study discovered and as indicated by studies of farmer stress, distress and suicide (Firth, Williams et al. 2007, Price and Evans 2009, Sadanandan 2014). Some of the darker emotional geographies of farming are captured in Convery et al's (2005) study on the 2001 British foot and mouth epidemic, which acted as a significant and shocking disjuncture in many farmers' relationships with their livestock. I suggest that 'enchantment' is therefore commonly used as a 'catch all' term for a variety of different embodied and emotional engagements. In my framing, I include both these 'positive' and 'negative' responses and argue that at least three different, yet interconnected, elements emerge which make an enchanting encounter ethically demanding:

1. A reflective, emotional connection to the actant which provoked the experience

2. A residual trace of the past (Ramsay 2009) and so a sense of responsibility to the predecessors legacy 
3. A hopeful reaching out to the future through the encouragement to revalue familiar farmscapes and see their capability to be other than they are

These are all present to varying degrees depending on the context of the encounter but, I would argue, are all necessary to establish Bennett's 'hopeful revaluation'. Enchantment is never constrained to particular interpretations of aesthetic landscapes, objects or subjects; even industrial and conventional agricultural systems - landscapes commonly decried as homogenous and monotonous except by farmers (Burton 2012) - can enchant those who work with them. I would not argue that enchantment is an innate quality of farming but the intensity of the relations many farmers have with their farms increases the potential opportunities to be enchanted; someone hiking through a farm may be equally enchanted by a landscape, a building or an animal but since their contact is less frequent, there is less potential for this embodied response.

By challenging how farmers experience their farms, enchantment enforces a constant, if unpredictable, renewal of their relationship with the place and other non-humans of the farm, which inspires and strengthens affective attachment (Woodyer and Geoghegan 2012). Being able to be enchanted allows for otherwise mundane experiences, practices, spaces and objects to be revalued, which encourages both the remembrance of why the farmer took up farming in the first place and, more generally, 'that it is good to be alive' (Bennett 2001: 156). The sense of fullness and enhanced responsiveness to other material forms that these enchanted connections promote is arguably psychologically beneficial, reinforcing positive feelings of possibility which in turn encourage a belief that here is something worth continuing. Through enhancing connections to the land, enchantment both increases the possibility of an ethical response of care - how and to whom being framed by the farmer - as well as attaching legitimacy to a farmer's practices and relations with the farm. The capacity to be enchanted therefore opens up complex moral economies through a host of care relations for the self, family, land, soil, plants, animals, buildings, technologies, colleagues and consumers and acts to strengthen the relationship between the farmer and the place of the farm. Since, following Maclean et al (2014) and Berkes and Ross (2013), I recognise the importance of people-place connections in enhancing social resilience, the experience of 
enchantment - through deepening and invigorating the spatial attachment, and hopeful appreciation of possibilities, of farmers - can therefore be a significant motivator for resilience at this personal scale.

\section{Conclusions}

Farmers have long played a significant role in shaping and maintaining rural landscapes, and their necessarily embodied practices and experiential knowledges create a very particular relationship between themselves and the land. While this can encourage a positive sense of connection and custodianship, it can equally act to constrain innovation with the common narrative of continuity (Riley 2008) sometimes acting to cement conservative socio-economic and environmental values. Nevertheless, whatever their impacts, these people-place connections form a significant element in developing social resilience (Maclean, Cuthill et al. 2014), supporting individuals and communities to adapt and become stronger when faced with challenges. Berkes and Ross (2013) called for a greater understanding of what actually bonds people and places and, in this paper, I propose enchantment as a key, but not exhaustive, element in enhancing this aspect of social resilience.

Recognising the enchanting qualities of everyday agricultural places, practices and objects makes space for their revaluation. While moments of wonder can perhaps be more easily understood within the ethos of hands-on, organic production even industrial agriculture contains opportunities for enchantment. These may not always be positive experiences of joy and wonder but I argue that even the emotional responses of frustration, rage and vulnerability can be enchanting given their capacity to highlight disjunctures that ensure a continual, yet unpredictable, renewal of the relationship between farmer and farm. This also works to question some of the assumed linkages between positive, embodied relationships with the land and 'alternative' agricultures. Recognising the capacity of industrial agricultural landscapes to enchant, the role of technology in changing, but not breaking, connections to the land and the importance of the darker emotional geographies allowed for a re-imagining of all farming relations and practices - whether organic or conventional - as embodied and fundamentally rooted in place. Combining the capacity to connect to the past, present and future, enchantment reminds a farmer of the initial attractions of farming, encourages a (re)appreciation of the farm 
landscapes and demands an active consideration of improvements; enchantment thus encourages a recognition that the world is not fixed but can be otherwise to how it habitually appears (Woodyer and Geoghegan 2012).

Lawson (2007) positions social relations achieved through such emotional connections as sites of power, and these relations of enchantment and care highlight how farmers are always enmeshed within complex, inter-temporal and spatially grounded webs consisting of the multitude of internal and external factors, human and non-human relations that shape their practices and understandings. The moral economies of the farm are therefore multiple, expansive and highly contextual as each farmer's relationship with their farm is dynamic, contingent and individual. Panarchy recognises that all systems consist of nested scales but, while I agree with this interconnected perspective, I would argue that more attention needs to be paid to the micro-scale as this is the level at which farmers experience and engage with their farms on an everyday, embodied and emotional basis. It is the social and power relations at this scale that therefore shape a farmer's connection to the farm-scape and so governs their capability to be socially resilient. Although used here to focus on farming, this discussion connects into broader debates around how relations of care emerge and can be promoted between, for example, consumers and producers (Starr 2009, Holt 2012, Wheeler 2012), humans and non-humans (Jones 2000, Kendall, Lobao et al. 2006, Holloway, Bear et al. 2014) and in terms of educating children and adults about the world and their roles within it. Enchantment can act as a powerful means to connect individuals and spaces and, I would argue, enhancing connections are key to addressing many of the challenges outlined by the farmers. However, as Berkes and Ross (2013) comment a resilient system is not always a desirable one, therefore a more holistic understanding of social resilience in agriculture is essential both to support the persistence and adaptation of desirable agricultural systems and to overcome the resilience of social and structural injustices and inequities. 


\section{Acknowledgements}

I would like to thank the School of Archaeology, Geography and Environmental Science at the University of Reading for supporting this pilot project as well as Richard Yarwood, Mike Goodman, the editor and two anonymous reviewers for their very helpful feedback. 


\section{References}

Adger, W. N. (2000). "Social and Ecological Resilience: are they related?" Progress in Human Geography 23: 347-364.

Adger, W. N., K. Brown, D. R. Nelson, F. Berkes, H. Eakin, C. Folke, K. Galvin, L. Gunderson, M. Goulden, K. O'Brien, J. Ruitenbeek and E. L. Tompkins (2011). "Resilience implications of policy responses to climate change." Wiley Interdisciplinary Review: Climate Change 2(5): 757-766.

Ahnström, J., J. Hockert, H. L. Bergea, C. A. Francis, P. Skelton and L. Hallgren (2008). "Farmers and Nature Conservation: what is known about attitudes, context factors and actions affecting conservation?" Renewable Agriculture and Food Systems 24(1): 38-47.

Allison, L. (1996). "On Planning a Forest pp. theoretical issues and practical problems." Town Planning Review 67(2): 131-143.

Arnold, T. C. (2001). "Rethinking Moral Economy." The American Political Science Review 95(1): 85-95.

Barnetson, B. (2012). "No Right to be Safe: justifying the exclusion of Alberta farm workers from health and safety legislations." Socialist Studies 8: 134-162.

Barnett, C., P. Cloke, N. Clarke and A. Malpass (2005). "Consuming Ethics: articulating the subjects and spaces of ethical consumption." Antipode 37(1): 23-45.

Beck, U. (1997). The Reinvention of Politics: rethinking modernity in the global social order. Cambridge, Polity Press.

Bennett, J. (2001). The Enchantment of Modern Life: attachments, crossings, and ethics. Princeton, Princeton University Press.

Berkes, F. and H. Ross (2013). "Community Resilience: towards an integrated approach." Society and Natural Resources 26: 5-20.

Bieling, C. and T. Plieninger (2003). "'Stinking, disease spreading brutes' or 'four-legged landscape managers'? Livestock, pastoralism, and society in Germany and the USA." Outlook on Agriculture 32: 7-12.

Björklund, J., H. Araya, S. Edwards, A. Goncalves, K. Höök, J. Lundberg and C. Medina (2012). "Ecosystem-Based Agriculture Combining Production and Conservation - a viable way to feed the world in the long term?" Journal of Sustainable Agriculture 36(7): 824-855.

Burlein, A. and J. Orr (2012). "Introduction. The Practice of Enchantment: strange allures." Women's Studies Quarterly 40(3\&4): 13-23.

Burton, R. J. F. (2004). "Seeing through the 'Good Farmer's' Eyes: towards developing an understanding of the social symbolic value of 'productivist' behaviour." Sociologia Ruralis 44(2): 195-215.

Burton, R. J. F. (2012). "Understanding Farmers' Aesthetic Preference for Tidy Agricultural Landscapes: a Bourdieusian perspective." Landscape Research 37(1): 51-71.

Burton, R. J. F., C. Kuczera and G. Schwarz (2008). "Exploring Farmers' Cultural Resistance to Voluntary Agrienvironmental Schemes." Sociologia Ruralis 48(1): 16-37.

Burton, R. J. F., S. Peoples and M. H. Cooper (2012). "Building 'Cowshed Cultures': a cultural perspective on the promotion of stockmanship and animal welfare on dairy farms." Journal of Rural Studies 28: 174-187. 
Burton, R. J. F. and G. A. Wilson (2006). "Injecting Social Psychology Theory into Conceptualisations of Agricultural Agency: towards a post-productivist farmer self-identity?" Journal of Rural Studies 22: 95-115.

Cadieux, K. V. and R. Blumberg (2013). Food Security in Systemic Context. Encyclopedia of Food and Agricultural Ethics. P. Thompson and D. M. Kaplan. London, Springer.

Carr, S. and J. Tait (1991). "Differences in the Attitudes of Farmers and Conservationists and Their Implications." Journal of Environmental Management 32: 281-294.

Chandler, D. (2013). "Resilience Ethics: responsibility and the globally embedded subject." Ethics \& Global Politics 6(3): 175-194.

Convery, I., C. Bailey, M. Mort and J. Baxter (2005). "Death in the Wrong Place? Emotional Geographies of the UK 2001 Foot and Mouth Disease Epidemic." Journal of Rural Studies 21: 99-109.

Cuthill, M., H. Ross, K. Maclean, K. Owens and B. Witt (2008). "Reporting Social Outcomes of Development: an analysis of diverse approaches." The International Journal of Interdisciplinary Social Science 3: 145-158.

Dale, A., C. Ling and L. Newman (2008). "Does Place Matter? Sustainable Community Development in Three Canadian Communities." Ethics, Place \& Environment 11: 267-281.

Darwar, A. (2013). Farmers: we must have more migrants. Daily Express. London.

DEFRA (2012). Agriculture in the United Kingdom. DEFRA. London.

DEFRA (2013). Future of Farming Review Report. London, DEFRA.

Dwiartama, A. and C. Rosin (2014). "Exploring Agency Beyong Humans: the compatibility of Actor-Network Theory (ANT) and resilience thinking." Ecology and Society 19(3): 28.

Emery, S. B. (2015). "Independence and Individualism: conflated values in farmer cooperation?" Agriculture and Human Values 32: 47-61.

Falconer, K. (2000). "Farm-Level Constraints on Agri-Environmental Scheme Participation: a transactional perspective." Journal of Rural Studies 16: 379-394.

Farming Regulation Task Force (2011). Striking a Balance: reducing burdens; increasing responsibility; earning recognition. London, DEFRA.

Firth, H. M., S. M. Williams, G.P.Herbison and R. O. McGee (2007). "Stress in New Zealand Farmers." $\underline{\text { Stress and }}$ Health 23(1): 51-58.

Folke, C. (2006). "Resilience: the emergence of a perspective for social-ecological systems analyses." Global Environmental Change 16: 253-267.

Forney, J. and P. V. Stock (2014). "Conversions of Family Farms and Resilience in Southland, New Zealand." International Journal of the Sociology of Agriculture and Food 21(1): 7-29.

Freidberg, S. (2014). "Moral Economics and the Cold Chain." Historical Research 88(239): 125-137.

Geoghegan, H. and C. Leyshon (2012). "On Climate Change and Cultural Geography: farming on the Lizard Peninsula, Cornwall, UK." Climatic Change 113: 55-66.

gov.uk. (2015). "Rural Development Programme for England." Retrieved 14 April, 2015, from https://www.gov.uk/rural-development-programme-for-england. 
Gray, J. (1996). "Cultivating Farm Life on the Borders: Scottish hill sheep farms and the European community." Sociologia Ruralis 36: 27-50.

Gray, J. (1999). "Open Spaces and Dwelling Places: being at home on hill farms in the Scottish Borders." American Ethnologist 26(2): 440-460.

Greenhill, J., D. King, A. Lane and C. MacDougall (2009). "Understanding Resilience in South Australian Farm Families." Rural Society 19(4): 318-325.

Hall, R., P. Wisborg, S. Shirinda and P. Zamchiya (2013). "Farm Workers and Farm Dwellers in Limpopo Province, South Africa." Journal of Agrarian Change 13(1): 47-70.

Hammond, B., G. Berardi and R. Green (2013). "Resilience in Agriculture: small- and medium-sized farms in Northwest Washington State." Agroecology and Sustainable Food Systems 37(3): 316-339.

Hansson, H. and C. J. Lagerkvist (2012). "Measuring Farmers' Attitudes to Animal Welfare and Health." British Food Journal 114(6): 840-852.

Harrison, C. M., J. Burgess and J. Clark (1998). "Discounted Knowledges: farmers' and residents' understandings of nature conservation goals and policies." Journal of Environmental Management 54: 305320.

Hayden, J. and D. Buck (2012). "Doing Community Supported Agriculture: tactile space, affect and effects of membership." Geoforum 43: 332-341.

Holloway, J. (2003). "Make-Believe: spiritual practice, embodiment, and sacred space." Environment and Planning A 35: 1961-1974.

Holloway, L. (2002). "Smallholding, hobby-farming, and commercial farming: ethical identities and production of farming spaces." Environment and Planning A 34: 2055-2070.

Holloway, L. (2003). ""What a thing, then, is this cow...": positioning domesticated lifestock animals in the texts and practices of small scale 'self sufficieny'." Society and Animals 11: 145-165.

Holloway, L., C. Bear and K. Wilkinson (2014). "Robotic Milking Technologies and Renegotiating Situated Ethical Relationships on UK Dairy Farms." Agriculture and Human Values 31: 185-199.

Holloway, L., C. Morris, B. Gilna and D. Gibbs (2009). "Biopower, Genetics and Livestock Breeding: (re)constituting animal populations and heterogenous biosocial collectivities." Transactions of the Institute of British Geographers 34: 394-407.

Holt-Giménez, E., A. Shattuck, M. Altieri, H. Herren and S. Gliessman (2012). "We Already Grow Enough Food for 10 Billion People...and Still Can't End Hunger." Journal of Sustainable Agriculture 36(6): 595-598.

Holt, D. B. (2012). "Constructing Sustainable Consumption: from ethical values to the cultural transformation of unsustainable markets." The Annals of the American Academy of Political and Social Science 644(1): 236255.

Howell, A. (2015). "Resilience as Enhancement: governmentality and political economy beyond 'responsibilisation'." Politics 35(1): 67-71.

Hunt, W., F. Vanclay, C. Birch, J. Coutts, N. Flittner and B. Williams (2011). "Agricultural Extension: building capacity and resilience in rural industries and communities." Rural Society 20(2): 112-127.

Jones, O. (2000). (Un)ethical Geographies of Human-Non Human Relations: encounters, collectives and spaces. Animal Spaces, Beastly Places: new geographies of human-animal relations. C. Philo and C. Wilbert. London, Routledge: 268 - 
Kendall, H. A., L. M. Lobao and J. S. Sharp (2006). "Public Concern with Animal Well-Being: place, social structural location, and individual experience." Rural Sociology 71(3): 399-428.

Latour, B. (2005). Reassembling the Social: an introduction to actor-network theory. Oxford, Oxford University Press.

Maclean, K., M. Cuthill and H. Ross (2014). "Six Attributes of Social Resilience." Journal of Environmental Planning and Management 57(1): 144-156.

Magis, K. (2010). "Community Resilience: an indicator of social sustainability." Society and Natural Resources 23: 401-416.

Maleksaeidi, H. and E. Karami (2013). "Social-Ecological Resilience and Sustainable Agriculture under Water Scarcity." Agroecology and Sustainable Food Systems 37(3): 262-290.

Marsden, T. and R. Sonnino (2008). "Rural Development and the Regional State: denying multifunctional agriculture in the UK." Journal of Rural Studies 24: 422-431.

McEwan, C. and M. K. Goodman (2010). "Place Geography and the Ethics of Care: introductory remarks on the geographies of ethics, responsibility and care." Ethics, Place \& Environment 13(2): 103-112.

Monbiot, G. (2013). Farming Subsidies: this is the most blatant transfer of cash to the rich. The Guardian. London.

Morris, C. (2006). "Negotiating the Boundary Between State-Led and Farmer Approaches to Knowing Nature: ana analysis of UK agri-environment schemes." Geoforum 37(1): 113-127.

Morris, C. and N. Evans (1999). "Research on the Geography of Agricultural Change: redundant or revitalized?" Area 31(4): 349-358.

Morris, C. and N. Evans (2004). "Agricultural Turns, Geographical Turns: retrospect and prospect." Journal of Rural Studies 20: 95-111.

Mueller Worster, A. and E. Abrams (2005). "Sense of Place among New England Commercial Fishermen and Organic Farmers: implications for socially constructed environmental education." Environmental Education Research 11(5): 525-535.

Nordström Källström, H. and M. Ljung (2005). "Social Sustainability and Collaborative Learning." Ambio 34: 376-382.

Price, L. and N. Evans (2009). "From Stress to Distress: conceptualizing the British family farming patriarchal way of life." Journal of Rural Studies 25: 1-11.

Ramsay, N. (2009). "Taking-Place: refracted enchantment and the habitual spaces of the tourist souvenir." Social \& Cultural Geography 10(2): 197-217.

Ranjan, R. (2014). "Multi-Dimensional Resilience in Water-Scarce Agriculture." Journal of Natural Resources Policy Research 6(2-3): 151-172.

Reimer, A. P., A. W. Thompson and L. S. Prokopy (2012). "The Multi-Dimensional Nature of Environmental Attitudes among Farmers in Indiana: implications for conservation adoption." Agriculture and Human Values 29: $29-40$.

Riley, M. (2008). "Experts in their Field: farmer-expert knowledges and environmentally friendly farming practices." Environment and Planning A 40: 1277-1293.

Ritzer, G. (2011). The McDonaldization of Society. Thousand Oaks, CA, Pine Forge Press. 
Rose, M. (2002). "Landscape and Labyrinths." Geoforum 33: 455-467.

Ryan, R. L., D. L. Erickson and R. d. Young (2003). "Farmers' Motivations for Adopting Conservation Practices along Riparian Zones in a Mid-western Agricultural Watershed." Journal of Environmental Planning and Management 46(1): 19-37.

Rye, J. F. and J. Andrzejewska (2010). "The Structural Disempowerment of Eastern European Migrant Farm Workers in Norwegian Agriculture." Journal of Rural Studies 26(1): 41-51.

Sadanandan, A. (2014). "Political Economy of Suicide: financial reforms, credit crunches and farmer suicides in India." The Journal of Developing Areas 48(4): 287-307.

Sayer, A. (2007). "Moral Economy as Critique." New Political Economy 12(2): 261-270.

Schneider, M. A. (1993). Culture and Enchantment. Chicago, University of Chicago Press.

Sellick, J. and R. Yarwood (2013). "Placing Livestock in Landscape Studies: pastures new or out to graze?" Landscape Research 38(4): 404-420.

Setten, G. (2004). "The Habitus, the Rule and the Moral Landscape." Cultural Geographies 11: 389-415.

Silvasti, T. (2003a). "The Cultural Model of 'The Good Farmer' and the Environmental Question in Finland." Agriculture and Human Values 20: 143-150.

Starr, M. A. (2009). "The Social Economic of Ethical Consumption: theoretical considerations and empirical evidence." The Journal of Socio-Economics 38(6): 916-925.

Stock, P. V. and J. Forney (2014). "Farmer Autonomy and the Farming Self." Journal of Rural Studies 36: 160171.

Sutherland, L.-A. (2013). "Can Organic Farmers be 'Good Farmers'? Adding the 'Taste of Necessity' to the Conventionalization Debate." Agriculture and Human Values 30: 429-441.

Thompson, C. J. and G. Coskuner-Balli (2007). "Enchanting Ethical Consumerism: the case of community supported agriculture." Journal of Consumer Culture 7(3): 275-303.

Thompson, E. P. (1971). "The Moral Economy of the English Crowd in the Eighteenth Century." Past and Present 50(February): 76-136.

Tilley, C. (2006). "Introduction: identity, place, landscape and heritage." Journal of Material Culture 11(1/2): 732.

UN. (2009). "Food Production Must Double by 2050 to Meet Demand from World's Growing Population, Innovative Strategies Needed to Combat Hunger, Experts Tell Second Committee." Retrieved 21 November, 2014, from http://www.un.org/press/en/2009/gaef3242.doc.htm.

Wheeler, K. (2012). Fairtrade and the Citizen-Consumer. London, Palgrave Macmillan.

Wilson, G. A. (2008). "From 'weak' to 'strong' multifunctionality: conceptualising farm-level multifunctional transitional pathways." Journal of Rural Studies 24: 367-383.

Wilson, G. A. (2009). "The Spatiality of Multifunctional Agriculture: a human geography perspective." Geoforum 40: 269-280.

Wilson, G. A. (2010). "Multifunctional 'Quality' and Rural Community Resilience." Transactions of the Institute of British Geographers 35(3): 364-381. 
Wilson, G. A. (2015). "Community Resilience and Social Memory." Environmental Values 24: 227-257.

Woodyer, T. and H. Geoghegan (2012). "(Re)enchanting Geography? The Nature of Being Critical and the Character of Critique in Human Geography." Progress in Human Geography 37(2): 195-214.

World Food Programme. (2014). "Hunger: hunger statistics." Retrieved 21 November, 2014, from https://www.wfp.org/hunger/stats.

Wylie, J. (2009). "Landscape, Absence and the Geographies of Love." Transactions of the Institute of British Geographers 34: 275-289.

Yarwood, R. and N. Evans (2006). "A Lleyn Sweep for Local Sheep? Breed Societies and the Geographies of Welsh Livestock." Environment and Planning A 38: 1307-1326.

Zanoli, R., D. Gambelli and F. Solfanelli (2014). "Assessing the Risk of Non-Compliance in UK Organic Agriculture." British Food Journal 116(8): 1369-1382. 